\title{
THREE-DIMENSIONAL SPECKLE TRACKING ECHOCARDIOGRAPHY FOR EVALUATION OF LEFT ATRIAL FUNCTION IN CORONARY ARTERY DISEASE PATIENTS WITH PRESERVED LEFT VENTRICLE EJECTION FRACTION
}

By

\author{
Taher Mohammed Abd El-Halem El-Meghwary, Kamal Ahmad \\ Merghny Mahgoub, Ahmad Ali Mohammed Fahim and Ahmed \\ Mohamed Abd El-Rahman
}

\author{
Department of Cardiology, Faculty of Medicine, Al-Azhar University
}

Correspondence author: Taher Mohammed Abd El-Halem,

E-mail: taher_elmeghwary@gmail.com

\begin{abstract}
Background: The left atrium (LA) is much more than simply a conduit for left ventricular (LV) filling, and its size and remodeling are recognized as a predictor of poor outcomes in multiple disease states. LA function is a surrogate marker of LV diastolic dysfunction.

Objective: To assess left atrial function in coronary artery disease patients with preserved left ventricle ejection fraction, with and without left atrial expansion by three dimensional speckle tracking echocardiograghy.

Patient and methods: Fifty patients with chronic coronary syndrome were divided according to left atrial dilation into two groups high risk group where left atrial dilation was more than $4 \mathrm{~cm}$ ( 8 males and 8 females) and low risk group where left atrial dilation was less than $4 \mathrm{~cm}$ (18 males and 16 females) in addition to 20 healthy individual as control group ( 7 males and 13 females) who presented to the Cardiology Department at Al-Hussain University Hospital and Al-Azhar Islamic Center for elective coronary angiography from May 2019 to June 2020.

Results: There was a statistically significant increase in control group in comparison to low risk and high risk. The LA peak ventricular systolic area strain (ASs \%) in patients group was significantly lower than in the control group, whereas in the low risk group was significantly higher than in the high risk group. The LA peak pre-atrial contraction area strain (ASa \%) in patients group was significantly lower than in the control group, whereas in the low risk group was significantly higher than in the high risk group.

Conclusion: Three-dimensional speckle tracking echocardiography represented a non-invasive, relatively simple and reproducible technique to assess left atrial myocardial function in patients with chronic coronary syndrome.
\end{abstract}

Keywords: Coronary heart disease, Chronic coronary syndromes, Left atrium, 3D-STE.

\section{INTRODUCTION}

Coronary heart disease (CAD) has the dynamic nature results in various clinical presentations, which can be conveniently categorized as either acute coronary syndromes (ACS) or chronic coronary syndromes (CCS). Those risks for future cardiovascular events, e.g. death or 
myocardial infarction (MI), and the risk may change over time (Knuuti et al., 2019).

The left atrium (LA) is much more than simply a conduit for left ventricular (LV) filling, and its size and remodeling are recognized as a predictor of poor outcomes in multiple disease states. LA dilation has been associated with increased risk of atrial fibrillation (AF), ischemic stroke, mortality after acute myocardial infarction, and heart failure with both reduced and preserved LV systolic function (Yoshida et al., 2011).

Assessment of LA function has been performed by measuring LA size or volume with two-dimensional (2D) echocardiography and Doppler echocardiographic measurements. A method known as strain imaging is used for the quantitative assessment of myocardial deformation. Three dimensional speckle tracking imaging has overcome the problems that faces twodimensional (2D) echocardiography and Doppler echocardiographic measurements by Area of strain that is the most sensitive parameter of LA function (Kleijn et al., 2011).

Speckle tracking echocardiography (STE) is a non-Doppler-based method for the objective quantification of myocardial deformation from standard bidimensional data sets (Cameli et al., 2011), and it allows to obtain the quantification of longitudinal myocardial LA deformation dynamics (Muranaka et al., 2010).

However, 2D imaging has several limitations. First, full LA segmental data are obtained from multiple planes in different cardiac cycles. Because of this non-simultaneous data acquisition, myocardial function may be altered beat by beat during unstable cardiac conditions. Second, the whole heart moves through the 2D plane of interest. Therefore, the 2D plane of interest disappears through a cardiac cycle, which is well known as the 'through-plane' or 'out-of plane phenomenon'. 3D fullvolume data acquisitions have the potential to overcome the limitation of plane-dependency of 2D imaging (Feigenbaum et al., 2012).

In three dimensional speckle tracking (3D-STE), area of strain is the most sensitive parameter of LA function, Area strain is a combination of longitudinal and circumferential deformations and is calculated by the rate of change in endocardial surface area from its original size (Kleijn et al., 2011).

This study was designed to assess left atrial function in coronary artery disease patients with preserved left ventricle ejection fraction with and without left atrial expansion by three dimensional speckle tracking echocardiograghy.

\section{PATIENTS AND METHODS}

Fifty patients with chronic coronary syndrome were divided according to left atrial dilatation into two groups: High risk group where left atrial dilation were more than $4 \mathrm{~cm}$ ( 8 males and 8 females) and low risk group where left atrial dilatation less than $4 \mathrm{~cm}$ (18 males and 16 females) in addition to 20 healthy individual as control group ( 7 males and 13 females) who presented to the Cardiology Department at Al-Hussain University Hospital, Al-Azhar Islamic Center for 


\section{THREE-DIMENSIONAL SPECKLE TRACKING ECHOCARDIOGRAPHY... 2059}

elective coronary angiography from May 2019 to June 2020.

Inclusion criteria: Patients more than 40 years old diagnosed as chronic coronary artery disease according to coronary angiography and have positive findings.

Exclusion criteria: All patients with history of congestive heart failure, moderate or severe valvular disease, congenital heart disease, conduction abnormalities, ongoing arrhythmia, pacemaker and acute coronary syndrome.

Each patient was subjected to the following after giving an informed consent:

i. History was taken including: (1) Age and gender. (2) Smoking recognized as a life time history of $>100$ cigarettes in their entire life and had continued smoking in the last 6 months was considered a positive smoking history. (3) Diabetic patients were recognized as having DM if they had history of DM on admission. (4) Dyslipidemia was defined by total cholesterol $\geq 220 \mathrm{mg} / \mathrm{dl}$. Hypertension was defined as systolic/diastolic blood pressure $\geq 140 / 90 \mathrm{mmHg}$ or patients had a history of hypertension. (6) Previous PCI procedures and previous CABG. (7) Anemic patients defined if haemoglobin level less than $14 \mathrm{gm} / \mathrm{dl}$ in males and less than $12 \mathrm{gm} / \mathrm{dl}$ in females. (8) Patient defined as renal impairment of creatinine clearance less than $70 \mathrm{ml} / \mathrm{min}$. (9) Other comorbid conditions, such as peripheral vascular disease.

\section{ii. A full clinical examination: Including vital signs, BMI and cardiac examination.}

iii. Electrocardiography: A 12-lead surface electrocardiography (ECG) was done for each patient on admission. The electrocardiograms were recorded at a paper with speed of $25 \mathrm{~mm} / \mathrm{s}$ and an amplification of 10 $\mathrm{mm} / \mathrm{mv}$.

iv. Laboratory investigations: Serum glycated haemoglobin (HbA1c) was measured. Serum creatinine was measured. The creatinine clearance was calculated. Admission complete blood count was measured. Lipid profile including, high density lipoprotein (HDL), low density lipoprotein (LDL), total cholesterol (TC) and triglycerides (TG) were measured.

Echocardiography was performed which included conventional M-mode, and 2-D transthoracic echocardiographic examination and Doppler study using standard parasternal and apical views to assess left ventricular diastolic function via transmitral mitral inflow velocities, left atrial volumes and left ventricular chamber dimensions, volume and function.

For 3D-STE analysis, we obtained apical full-volume acquisition to visualize the entire left atrium in a volumetric image as apyramidal volume. Each 3D data set was displayed in a five-plane view: (A) an apical four chamber view, (B) a second apical view orthogonal to plane $\mathrm{A}$, and $(\mathrm{C})$ three short-axis planes, including plane $\mathrm{C} 1$ in the basal potion, plane $\mathrm{C} 2$ in the mid left atrium, and plane $\mathrm{C} 3$ at the roof portion of the left atrium 
plane, one marker is set at the roof of the left atrium, and the other two are set at the edges of the mitral annulus. The software then detects the LA endocardium using a semi-automated contour-tracing algorithm, and the user sets LA wall thickness to the smallest possible value. The software divides the left atrium into 16 segments. After the markers have been selected, the system performs wall motion-tracking analysis through the entire cardiac cycle and enables the calculation of maximal LA volume. The following parameters were measured: LA peak ventricular systolic area strain (ASs) and LA peak pre-atrial contraction area strain (ASa).

\section{Statistical analysis:}

Results of the present study were statistically analyzed using SPSS 25 (IBM, USA). Data were represented as median (interquartile range) or number and percentage. Numerical data were compared using one-way ANOVA followed by post hoc test, while categorical data were compared using Fisher exact test or Chi-square test as appropriate. ROC curve was used to evaluate the performance of different tests differentiate between certain groups. The level of significance at $\mathrm{P}$ value $<0.050$ was significant.

\section{RESULTS}

Fifty patients with chronic coronary syndrome were divided into two groups: high risk (mean age 57.75 \pm 7.66 years, 8 males and 8 females) and low risk (mean age 55.26 6.19 years, 18 males and 16 females) and 20 healthy individual as control group (mean age 56.70 \pm 4.54 years, 7 males and 13 females). There was no statistically significant difference in demographic data regarding studied group (Table 1).

Table (1): Comparison between high risk, low risk \& control group as regards demographic data

\begin{tabular}{|c|c|c|c|c|c|c|c|c|}
\hline \multirow{2}{*}{\multicolumn{2}{|c|}{ Parameters Groups }} & \multicolumn{2}{|c|}{$\begin{array}{c}\text { Control } \\
(\text { No.=20) }\end{array}$} & \multicolumn{2}{|c|}{$\begin{array}{c}\text { High risk } \\
(\text { No.=16) }\end{array}$} & \multicolumn{2}{|c|}{$\begin{array}{l}\text { Low risk } \\
(\text { No.=34) }\end{array}$} & \multirow{2}{*}{$\begin{array}{c}\begin{array}{c}\text { Chi square test/ } \\
\text { One way ANOVA }\end{array} \\
\text { P value }\end{array}$} \\
\hline & & No & $\%$ & No & $\%$ & No & $\%$ & \\
\hline \multirow{2}{*}{ Sex, n $(\%)$} & Female & 13 & $65.0 \%$ & 8 & $50.0 \%$ & 16 & $47.1 \%$ & \multirow{2}{*}{0.429} \\
\hline & Male & 7 & $35.0 \%$ & 8 & $50.0 \%$ & 18 & $52.9 \%$ & \\
\hline Age(years) & Mean \pm SD & 56.70 & 4.54 & 57.75 & 7.66 & 55.26 & 6.19 & 0.386 \\
\hline
\end{tabular}

There was a statistically significant increase in high risk in comparison to low risk with left ventricular end-diastolic volume (LVEDV). The left ventricular end systolic volume (LVESV), left ventricular ejection fraction (LVEF)\%, left anterior descending (LAD), maximum left atrial volume (LAV max.), minimum left atrial volume (LAV min.) and E/A, but there was a statistically significant increase in low with left atrial volumes (LAV) ejection fraction (EF)\%, E and A (Table 2). 
THREE-DIMENSIONAL SPECKLE TRACKING ECHOCARDIOGRAPHY... 2061

Table (2): Comparison between high risk, low risk \& control group as regards echocardiographic changes

\begin{tabular}{|c|c|c|c|c|c|c|c|}
\hline \multirow{2}{*}{ Parameters } & \multicolumn{2}{|c|}{$\begin{array}{l}\text { Control } \\
(\text { No. }=20)\end{array}$} & \multicolumn{2}{|c|}{$\begin{array}{l}\text { High risk } \\
(\text { No. }=16)\end{array}$} & \multicolumn{2}{|c|}{$\begin{array}{l}\text { Low risk } \\
(\text { No.=34) }\end{array}$} & \multirow{2}{*}{$\begin{array}{c}\text { One way } \\
\text { ANOVA } \\
\text { P value }\end{array}$} \\
\hline & Mean & SD & Mean & SD & Mean & SD & \\
\hline LVEDV $(\mathrm{ml})$ & 82.70 & 12.68 & 115.69 & 1.54 & 109.82 & 2.96 & $<0.001$ \\
\hline LVESV $(\mathrm{ml})$ & 31.91 & 7.09 & 51.51 & 1.50 & 44.59 & 3.27 & $<0.001$ \\
\hline $\operatorname{LVEF}(\%)$ & 55.44 & 0.73 & 60.70 & 2.92 & 58.92 & 2.08 & $<0.001$ \\
\hline $\mathrm{LAD}(\mathrm{cm})$ & 2.97 & 0.30 & 4.33 & 0.11 & 3.35 & 0.48 & $<0.001$ \\
\hline LAV max. (ml) & 18.70 & 3.06 & 26.39 & 1.04 & 20.30 & 2.03 & $<0.001$ \\
\hline LAV min. (ml) & 9.99 & 2.16 & 16.60 & 1.35 & 10.07 & 1.80 & $<0.001$ \\
\hline LAV EF (\%) & 47.00 & 2.97 & 37.25 & 2.62 & 50.15 & 4.65 & $<0.001$ \\
\hline $\mathrm{E}(\mathrm{c} / \mathrm{s})$ & 68.85 & 12.14 & 41.81 & 2.51 & 67.32 & 9.92 & $<0.001$ \\
\hline $\mathrm{A}(\mathrm{c} / \mathrm{s})$ & 69.13 & 5.24 & 44.50 & 24.12 & 80.03 & 23.16 & $<0.001$ \\
\hline $\mathrm{E} / \mathrm{A}$ & 99.25 & 20.47 & 133.50 & 10.48 & 87.09 & 12.41 & $<0.001$ \\
\hline \multicolumn{8}{|l|}{ Post hoc test } \\
\hline & \multicolumn{2}{|c|}{ Control VS low risk } & \multicolumn{3}{|c|}{ Control VS high risk } & \multicolumn{2}{|c|}{$\begin{array}{c}\text { High risk VS low } \\
\text { risk }\end{array}$} \\
\hline LVEDV & \multicolumn{2}{|c|}{0.001} & \multicolumn{3}{|c|}{0.001} & \multicolumn{2}{|c|}{0.008} \\
\hline LVESV & \multicolumn{2}{|c|}{0.001} & \multicolumn{3}{|c|}{0.001} & \multicolumn{2}{|c|}{0.001} \\
\hline $\mathrm{LVEF} \%$ & \multicolumn{2}{|c|}{0.005} & \multicolumn{3}{|c|}{0.001} & \multicolumn{2}{|c|}{0.001} \\
\hline LAD & \multicolumn{2}{|c|}{0.001} & \multicolumn{3}{|c|}{0.001} & \multicolumn{2}{|c|}{0.001} \\
\hline LAV max. & \multicolumn{2}{|c|}{0.013} & \multicolumn{3}{|c|}{0.001} & \multicolumn{2}{|c|}{0.001} \\
\hline LAV min. & \multicolumn{2}{|c|}{0.871} & \multicolumn{3}{|c|}{0.001} & \multicolumn{2}{|r|}{0.871} \\
\hline LAV EF\% & \multicolumn{2}{|c|}{0.005} & \multicolumn{3}{|c|}{0.001} & \multicolumn{2}{|c|}{0.005} \\
\hline $\mathrm{E}$ & \multicolumn{2}{|c|}{0.573} & \multicolumn{3}{|c|}{0.001} & \multicolumn{2}{|c|}{0.001} \\
\hline $\mathrm{A}$ & & & & 0.00 & & & 0.001 \\
\hline $\mathrm{E} / \mathrm{A}$ & & & & 0.00 & & & 0.001 \\
\hline
\end{tabular}

LVEDV = Left ventricle end diastolic volume; LVESV=Left ventricle end systolic volume; LVEF\% $=$ LV ejection fraction; $\mathrm{LAD}=$ Left atrial dimension; LAV max. = Maximum left atrial volume; LAV min. = Minimum left atrial volume; $\mathrm{LAEF}=$ Left atrial emptying fraction; E=Early diastolic velocity; A =Late diastolic velocity.

There was a statistically significant increase in control group in comparison to low risk and high risk with 3D speckle tracking (Table 3).

Table (3): Comparison between high risk, low risk \& control group as regards 3D speckle tracking

\begin{tabular}{|c|c|c|c|c|c|c|c|c|}
\hline \multirow{2}{*}{ Groups } & \multicolumn{2}{|c|}{$\begin{array}{l}\text { Control } \\
(\text { No. }=20)\end{array}$} & \multicolumn{2}{|c|}{$\begin{array}{l}\text { High risk } \\
\text { (No.=16) }\end{array}$} & \multicolumn{2}{|c|}{$\begin{array}{l}\text { Low risk } \\
(\text { No. }=34)\end{array}$} & \multicolumn{2}{|c|}{ One way ANOVA } \\
\hline & Mean & SD & Mean & SD & Mean & SD & $\mathbf{f}$ & P value \\
\hline $\operatorname{ASs}(\%)$ & 78.50 & 9.65 & 28.69 & 10.90 & 61.82 & 6.04 & 158.918 & $<0.001$ \\
\hline $\operatorname{Asa}(\%)$ & 40.70 & 6.42 & 14.50 & 4.75 & 31.06 & 3.96 & 126.065 & $<0.001$ \\
\hline \multicolumn{9}{|l|}{ Post hoc test } \\
\hline & \multicolumn{3}{|c|}{ Control VS low risk } & \multicolumn{2}{|c|}{ Control VS high risk } & \multicolumn{3}{|c|}{ High risk VS low risk } \\
\hline ASs & \multicolumn{3}{|c|}{0.001} & \multicolumn{2}{|c|}{0.001} & \multicolumn{3}{|c|}{0.001} \\
\hline $\mathrm{ASa}$ & \multicolumn{2}{|c|}{0.001} & & \multicolumn{2}{|c|}{0.001} & \multicolumn{3}{|c|}{0.001} \\
\hline
\end{tabular}

LA peak pre-atrial contraction area strain. $\mathrm{ASa}=\mathrm{ASs}=\mathrm{LA}$ peak ventricular systolic area strain; 
ASs has positive correlations with Asa, CRCL, LVEF\%, LAV EF\%, E and A but has negative correlations with CR, HbA1C, LVEDV, LVESV, LAD, LAV max., LAV min, E/A and Coronary score. Also, ASa has positive correlations with
ASa, CRCL, LVEF\%, LAV EF\%, E and A, but has negative correlations with CR, HbA1C, LVEDV, LVESV, LAD, LAV max., LAV min, E/A and coronary score in case group (Table 4).

Table (4): Correlation between 3D speckle tracking among studied parameters in case group

\begin{tabular}{|l|c|c|c|c|}
\hline \multirow{2}{*}{ Parameters } & \multicolumn{2}{|c|}{ ASs } & \multicolumn{2}{c|}{ ASa } \\
\cline { 2 - 5 } & r & P value & r & P value \\
\hline ASa & 0.989 & 0.001 & -- & -- \\
\hline Age & -0.137 & 0.341 & -0.170 & 0.237 \\
\hline Height & 0.121 & 0.402 & 0.119 & 0.412 \\
\hline Weight & 0.036 & 0.803 & 0.030 & 0.838 \\
\hline BMI & -0.045 & 0.758 & -0.042 & 0.772 \\
\hline HB & -0.138 & 0.341 & -0.160 & 0.267 \\
\hline CR & -0.343 & 0.015 & -0.371 & 0.008 \\
\hline CRCL & 0.382 & 0.006 & 0.402 & 0.004 \\
\hline LDL & -0.095 & 0.512 & -0.076 & 0.601 \\
\hline TG & -0.139 & 0.336 & -0.092 & 0.523 \\
\hline HDL & 0.012 & 0.934 & 0.015 & 0.918 \\
\hline HbA1C & -0.463 & 0.001 & -0.483 & 0.001 \\
\hline LVEDV & -0.987 & 0.001 & -0.978 & 0.001 \\
\hline LVESV & -0.988 & 0.001 & -0.980 & 0.001 \\
\hline LVEF\% & 0.821 & 0.001 & 0.842 & 0.001 \\
\hline LAD & -0.994 & 0.001 & -0.984 & 0.001 \\
\hline LAV max. & -0.992 & 0.001 & -0.984 & 0.001 \\
\hline LAV min. & -0.994 & 0.001 & -0.987 & 0.001 \\
\hline LAV EF\% & 0.940 & 0.001 & 0.914 & 0.001 \\
\hline E & 0.995 & 0.001 & 0.985 & 0.001 \\
\hline A & 0.896 & 0.001 & 0.886 & 0.001 \\
\hline E/A & -0.996 & 0.001 & -0.991 & 0.001 \\
\hline GS & -0.704 & 0.001 & -0.730 & 0.001 \\
\hline SS & -0.663 & 0.001 & -0.691 & 0.001 \\
\hline
\end{tabular}

$\mathrm{ASa}=\mathrm{LA}$ peak pre-atrial contraction area strain; ASs = LA peak ventricular systolic area strain; BMI: Body mass index; HB=Hemoglobin in blood; $\mathrm{CR}=$ Creatinine; $\mathrm{CRCL}$ : Creatinine Clearance; LDL-C = low-density lipoprotein cholesterol; TG= triglycerides; HDL-C $=$ high density lipoprotein cholesterol; HbA1c $=$ glycated haemoglobin; LVEDV = Left ventricle end diastolic volume; LVESV=Left ventricle end systolic volume; $\mathrm{LVEF}=\mathrm{LV}$ ejection fraction; $\mathrm{LAD}=$ Left atrial dimension; $\mathrm{LAV}$ max. = Maximum left atrial volume; $\mathrm{LAV}$ min. = Minimum left atrial volume; LAEF = Left atrial emptying fraction; E=Early diastolic velocity; A $=$ Late diastolic velocity; GS $=$ Ginsini Score; SS $=$ SYNTAX Score.

\section{DISCUSSION}

This study was conducted aiming to assess the left atrial function in coronary artery disease patients with preserved left ventricle ejection fraction with and without left atrial expansion by three dimensional speckle tracking echocardiograghy.

The current study revealed that no statistically significant differences were 


\section{THREE-DIMENSIONAL SPECKLE TRACKING ECHOCARDIOGRAPHY... 2063}

found among the study groups (high risk, low risk and controls) as regards age, sex. This balance in the baseline characteristics provides the basis for comparison between the study groups as it helps to minimize bias (Sedgwick, 2014).

The current study revealed that no statistically significant differences were found between the high risk and low risk study groups as regards past history of ischemic heart disease or family history. This balance in the baseline characteristics helps to minimize bias when comparing between the study groups (Sedgwick, 2014).

The current study revealed that no statistically significant differences were found between the high risk and low risk study groups as regards ECG findings. This absence of significant ECG changes with different atrial volume might be explained by the finding that none of the commonly used ECG left or right atrial enlargement criteria provided high accuracy for detecting anatomic left or right atrial enlargement and that high sensitivity was achieved only with lower specificity and vice versa. Furthermore, hypertension may affect $\mathrm{P}$ wave characteristics on ECG independently of atrial size (Tsao et al., 2012).

The current study revealed that no statistically significant differences were found among the study groups (high risk, low risk and controls) as regards the mean results of some of the performed laboratory investigations namely: hemoglobin level, creatinine level, creatinine clearance and triglycerides level. Meanwhile, statistically significant differences were found among the three groups as regards LDL and HDL levels (with the significant differences being found when control group was compared versus either high risk or low risk groups) as well as in $\mathrm{HbA1C}$ level (with the significant differences being found when control group was compared versus either high risk or low risk groups as well as when comparing high risk group versus low risk group) (Rayyan et al., 2012).

Statistically significant differences were found among the three groups as regards all studied echocardiographic findings which were found with pairwise comparisons in case of LVEDV, LVESV, LVEF\%, LAD, LAV max., LAV EF\%, A and E/A. On the other hand, the statistically significant difference in case of LAV min. was found only between the control and high risk group and in case of $\mathrm{E}$ between the high risk group and either the controls or low risk group. Statistically significant differences also were found among the three groups as regards 3D speckle tracking findings which were found with pairwise comparisons in case of ASs and $\mathrm{ASa}$ with their mean values being lowest in the high risk group. There were statistically significant differences between the high and low risk groups as regards the coronary score with higher GS and SS mean values being found in the high risk group (Elmedany et al., 2017).

No statistically significant correlations were found between either age, height, weight, body mass index (BMI), hemoglobin level, LDL level, HDL level, TG level on one hand and either ASs or $\mathrm{ASa}$ on the other hand. Meanwhile, a strong positive correlation was found between ASs and ASa as well as between $\mathrm{LVEF} \%$, LAV EF\%, E and A on one hand and ASs and ASa on the other hand. 
Furthermore, a moderate positive correlation was found between CRCL and both ASs and ASa. Moderate negative correlation was found between $\mathrm{CR}$, HBA1C SS and GS on one hand and ASs and ASa on the other hand. A strong negative correlation was found between LVEDV, LVESV, LAD, LAV max., LAV min. and E/A on one hand and ASs and ASa on the other hand (Halilbašić et al., 2014).

\section{CONCLUSION}

Three-dimensional speckle tracking echocardiography represented a noninvasive, relatively simple and reproducible technique to assess left atrial myocardial function in patients with chronic coronary syndrome. The reservoir and conduit function of the left atrium were impaired in these patients compared with controls, LA peak ventricular systolic area strain and LA peak pre-atrial contraction area strain were significantly positive correlated with both left atrium 2D Doppler echocardiographic parameters and LV contractile function and could be suggested as a better indicator to evaluate LA function as a preferred parameter of Speckle tracking echocardiography.

\section{REFERENCES}

1. Cameli M, Caputo M, Mondillo S, Palmerini E, Lisi M, Marino E and Galderisi M. (2011): Feasibility and reference values of left atrial longitudinal strain imaging by twodimensional speckle tracking. Cardiovasc. Ultrasound, 7: 6-9.

2. Elmedany, S. M., Naga, S. S., Elsharkawy, R., Mahrous, R. S., \& Elnaggar, A. I. (2017): Novel urinary biomarkers and the early detection of acute kidney injury after open cardiac surgeries. Journal of critical care, 40, 171-177.

3. Feigenbaum $H$, Mastouri $R$ and Sawada S. (2012): A practical approach to using strain echocardiography to evaluate the left ventricle. Circ J., 76: 1550-1555.

4. Halilbašić, M., Zvorničanin, J., Jusufović, V., Čabrić, E., Halilbašić, A., Mušanović, Z., \& Međedović, A. (2014): Pediatric cataract in Tuzla Canton, Bosnia and herzegovina. Med Glas (Zenica), 11(1), 127-131.

5. Kleijn SA, Aly MF, Terwee CB, van Rossum AC and Kamp O. (2011): Three-dimensional speckle tracking echocardiography for automatic assessment of global and regional left ventricular function based on area strain. J Am Soc Echocardiogr., 24:314-21.

6. Knuuti J, Wijns $W$ and Saraste A. (2019): ESC Guidelines for the diagnosis and management of chronic coronary syndromes: The Task Force for the diagnosis and management of chronic coronary syndromes of the European Society of Cardiology (ESC). Eur Heart Journal, 71: 101093-97.

7. Muranaka A, Yuda S, Tsuchihashi K, Hashimoto A, Nakata T, Miura T, Tsuzuki M, Wakabayashi C, Watanabe $N$ and Shimamoto $K$. (2010): Quantitative assessment of left ventricular and left atrial functions by strain rate imaging in diabetic patients with and without hypertension. Echocardiography, 26(3):262-271. 
THREE-DIMENSIONAL SPECKLE TRACKING ECHOCARDIOGRAPHY... 2065

8. Rayyan, M., Devlieger, H., Jochum, F., \& Allegaert, K. (2012): Short-term use of parenteral nutrition with a lipid emulsion containing a mixture of soybean oil, olive oil, medium-chain triglycerides, and fish oil: a randomized double-blind study in preterm infants. Journal of Parenteral and Enteral Nutrition, 36, 81S-94S.

9. Sedgwick P. (2014): Randomized controlled trials: Balance in baseline characteristics. BMJ, 349(3): 5721.

10. Tsao CW, Josephson ME, Hauser TH, O'Halloran TD (2012): Accuracy of electrocardiographic criteria for atrial enlargement: validation with cardiovascular magnetic resonance. $\mathbf{J}$ Cardiovasc Magn Reson., 10(1):7-11.

11. Yoshida C, Nakao S, Goda A and Naito Y (2011): Value of assessment of left atrial volume and diameter in patients with heart failure but with normal left ventricular ejection fraction and mitral flow velocity pattern. Eur J Echocardiogr., 10(2):278-81. 


\section{إستخدام التتبع النقطي ثلاثي الأبعاد لتقيييم وظيفة الأذين الأيسر

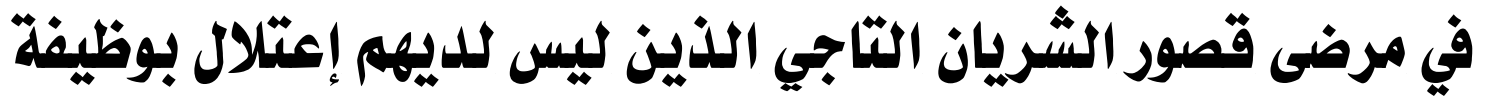 الاقلب}

طاهر محمد عبد الحليم المغوري، كمال أحمد مرغني محجوب، أحمد علي محمد فهيم،

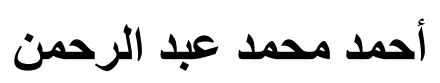

قسم القلب والأوعية الاموية، كلية الطب، جامعة الأزهر

E-mail: taher_elmeghwary@gmail.com

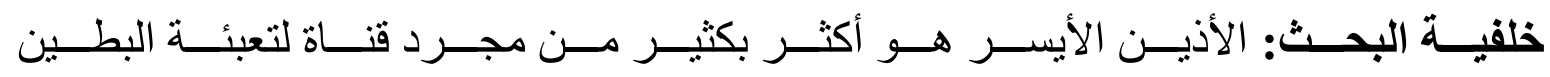

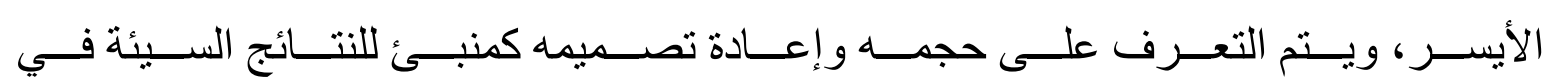

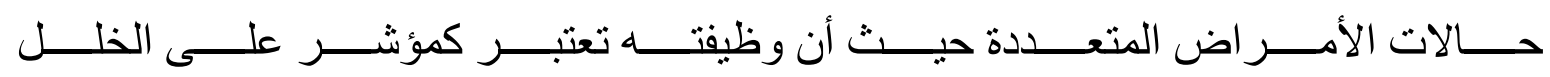

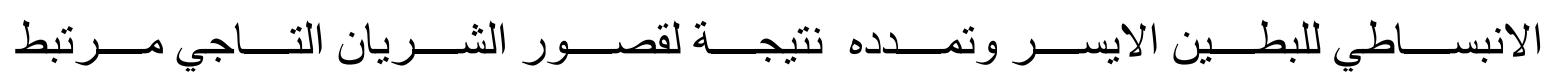

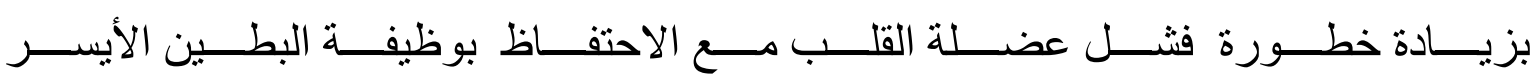
الانقباضية.

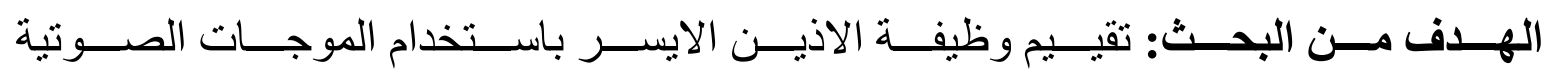

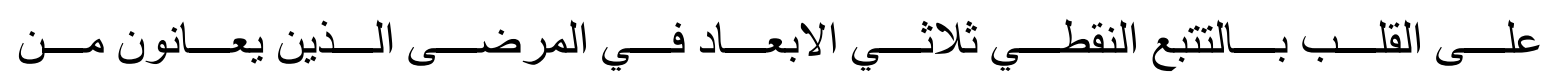
متلازمة الثريان التاجي المزمن مقارنة مع الاصحاء.

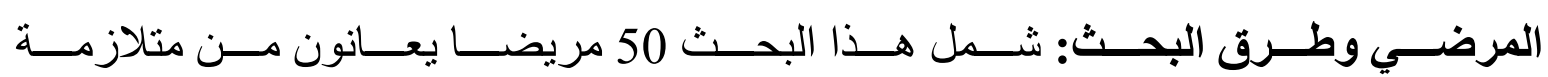

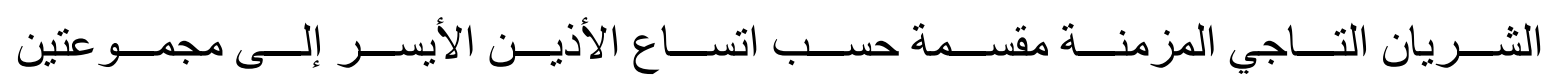

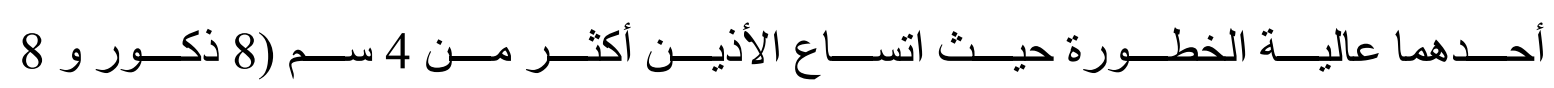

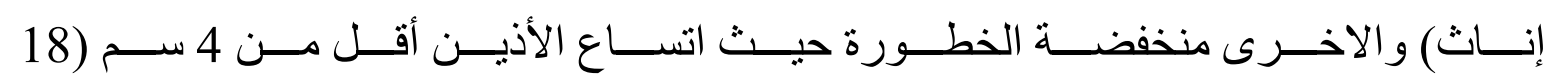

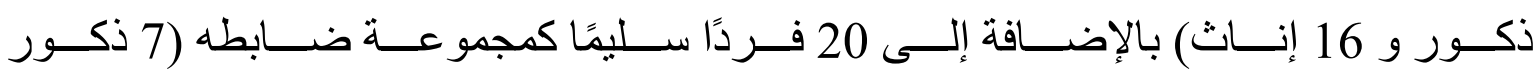

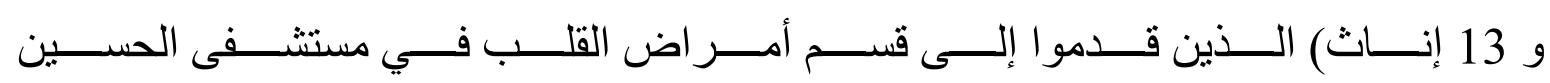

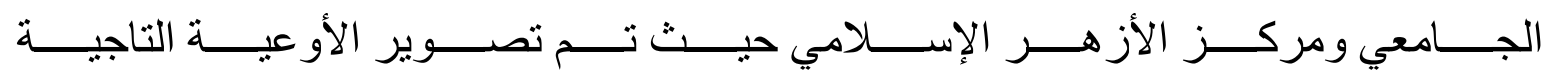
الاختيارية وذللك فى الفترة من شهر مايو 2019 الى شهر يونيو 2020. 


\section{THREE-DIMENSIONAL SPECKLE TRACKING ECHOCARDIOGRAPHY... ${ }^{2067}$}

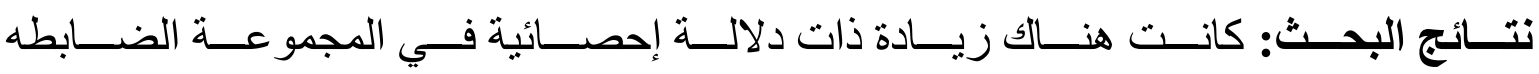

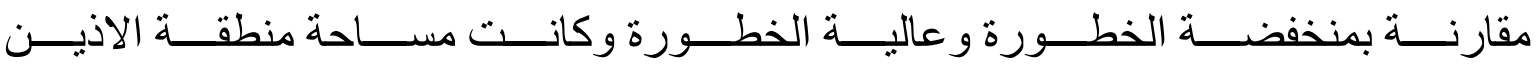

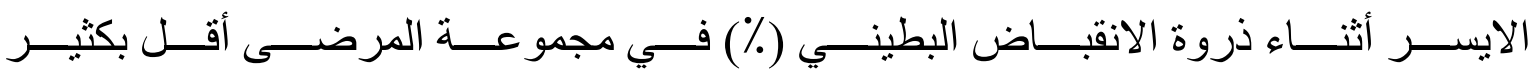

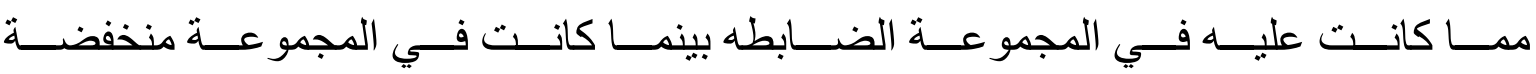

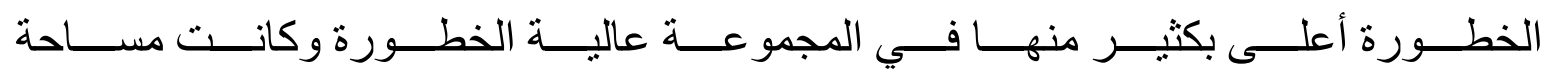

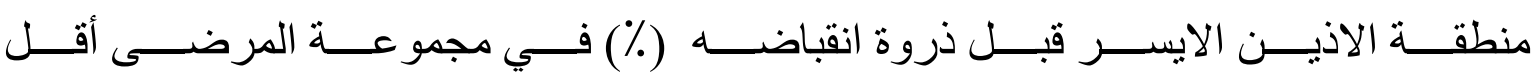

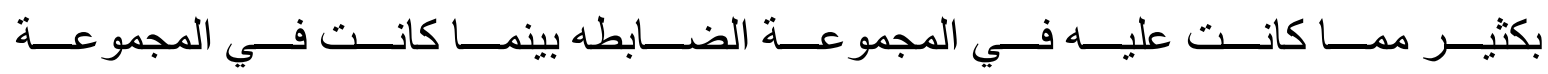
منخفضة الخطورة أعلى بكثثر منها في المجموعة عالية الخطورة.

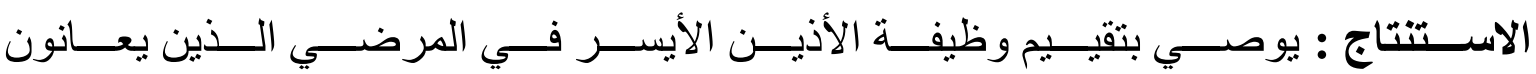

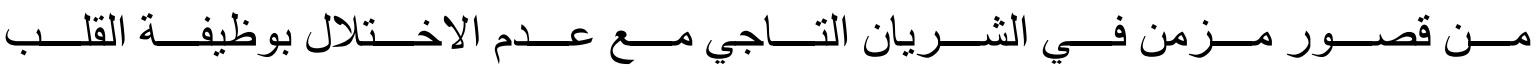

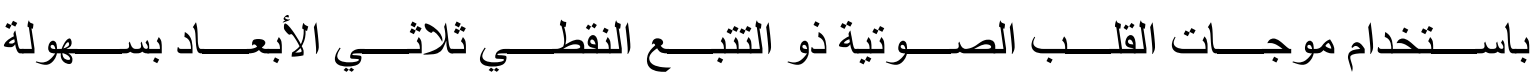

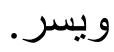

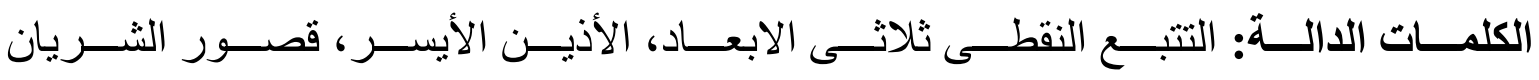
التاجى، إعتلال وظيفة القلب. 